Fabien Arnaud ${ }^{1}$, Cécile Pignol' ${ }^{1}$ Bruno Galabertier ${ }^{1}$, Xavier Crosta ${ }^{2}$, Isabelle Billy², Elodie Godinho ${ }^{3}$, Karim Bernardet $^{3}$, Pierre Sabatier ${ }^{1}$, Anne-Lise Develle ${ }^{1}$, Rosalie Bruel ${ }^{1,4}$, Julien Penguen ${ }^{5}$, Pascal Calvat ${ }^{5}$, Pierre Stéphan ${ }^{6}$, and Mathias Rouan ${ }^{6}$

\section{The pyramid of data: general case}

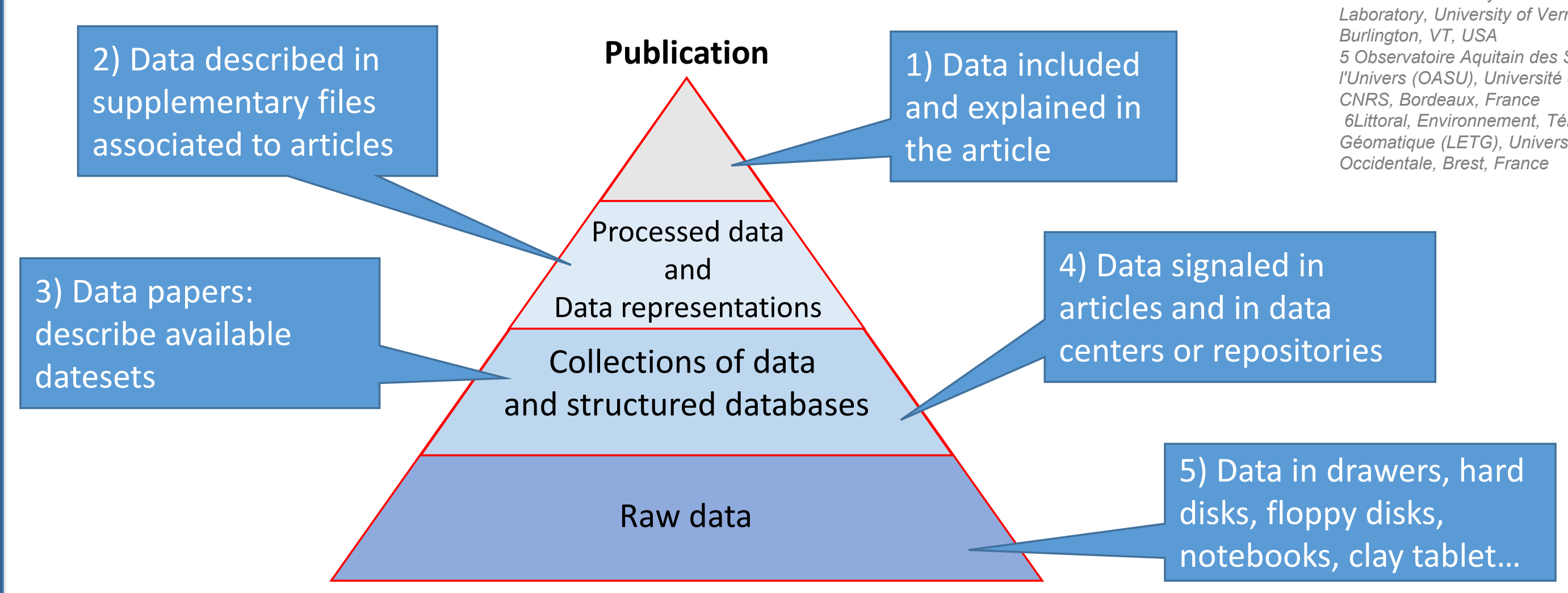

Adapted from Report on integration of data and publications. Opportunities for data exchange (Relly et al., 2011) 


\section{Publications are just the emerged tip of a huge iceberg of « frozen » data}

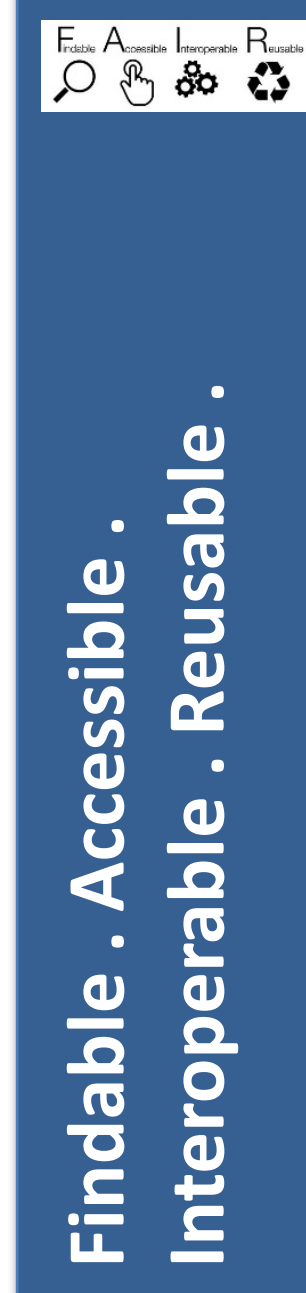

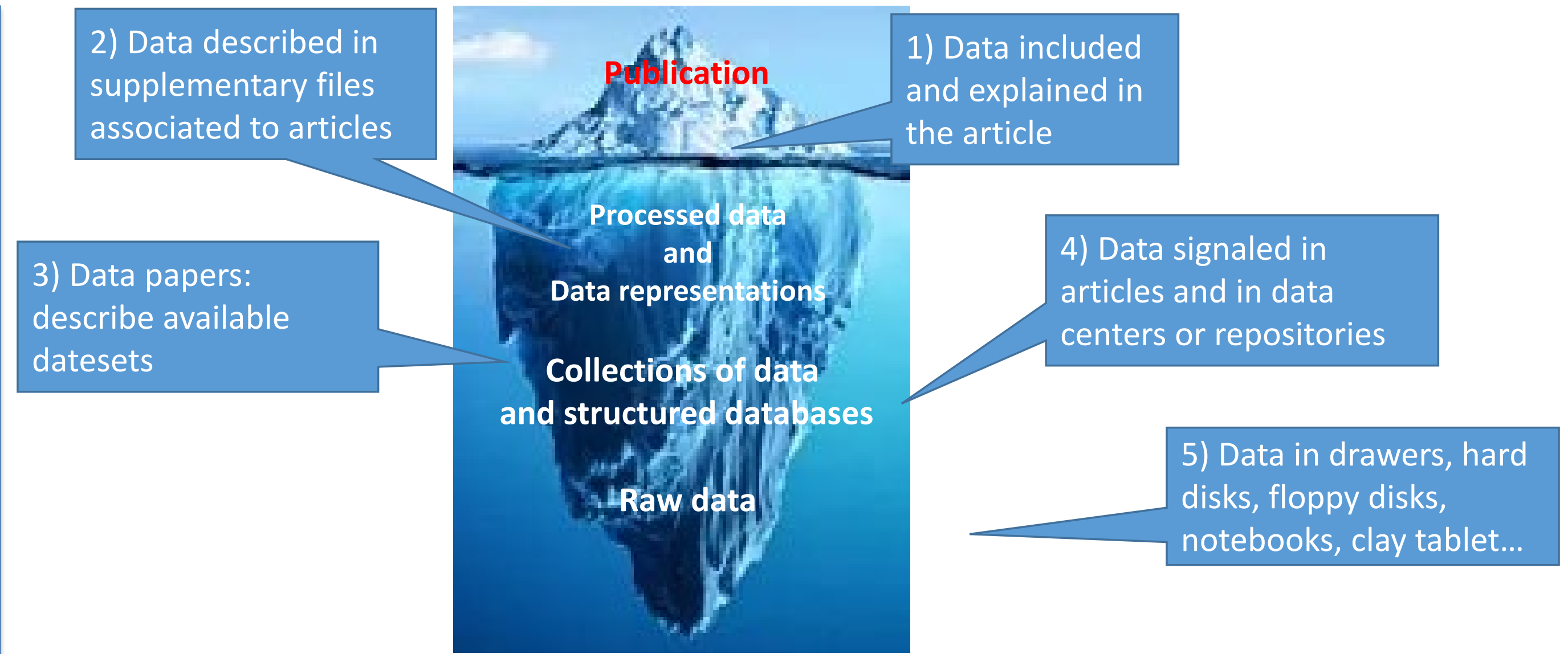


The pyramid of data: case of field-based (geo)sciences

PANGAEA or NOAA portals permit to store and find published datasets

There is no raw data repository nor standard in sample-based geoscience

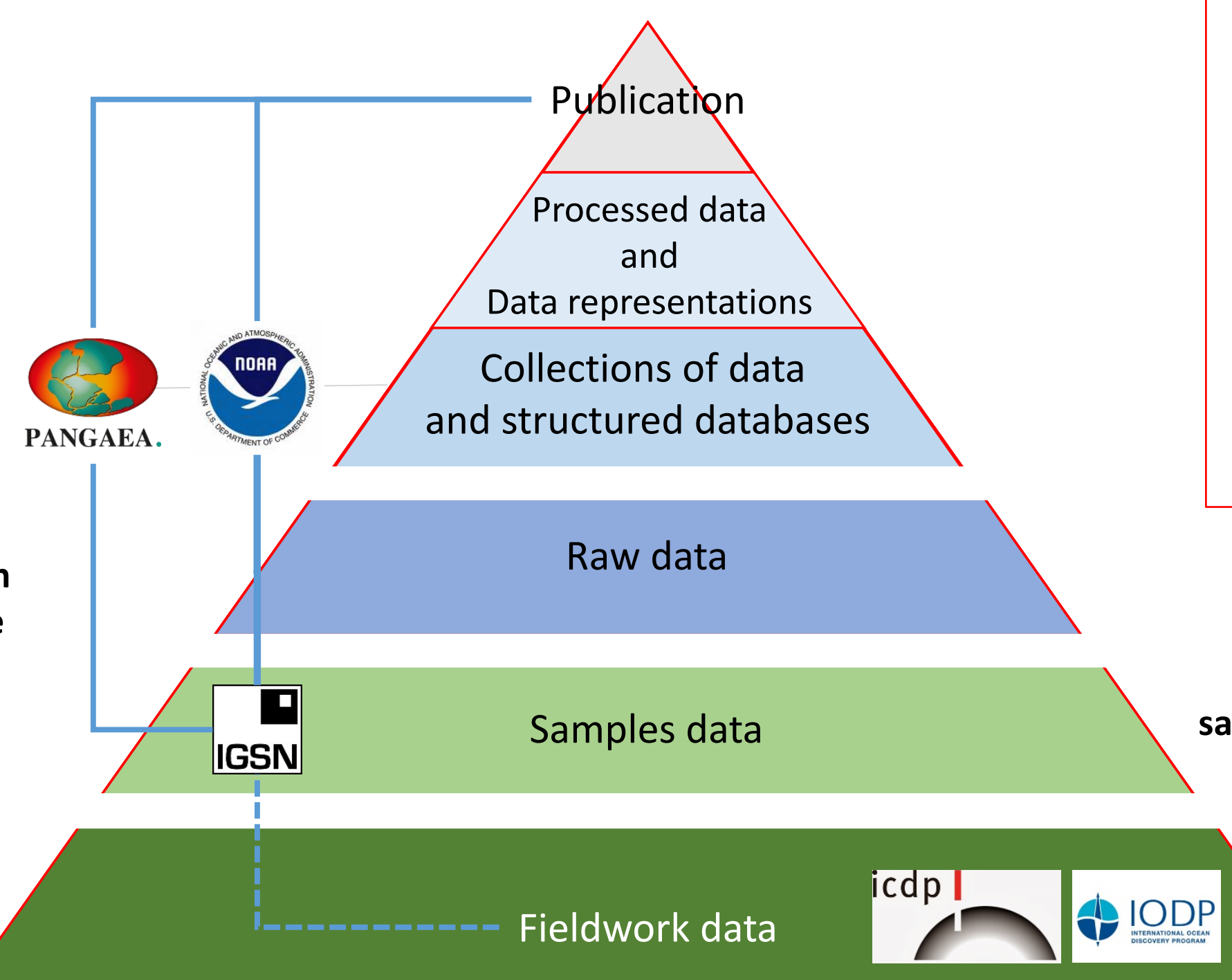

\section{Samples and field data are the absolutely necessary foundations of the whole pyramid}

\section{However, they are often poorly banked}

IGSN offers the opportunity to link samples and data but includes only poor fieldwork data

Fieldwork data are sometimes banked at single-project scale, not for every researcher 
The pyramid of data: case of field-based (geo)sciences

Would be great to have dedicated tools to bank data from fieldwork to the lab!
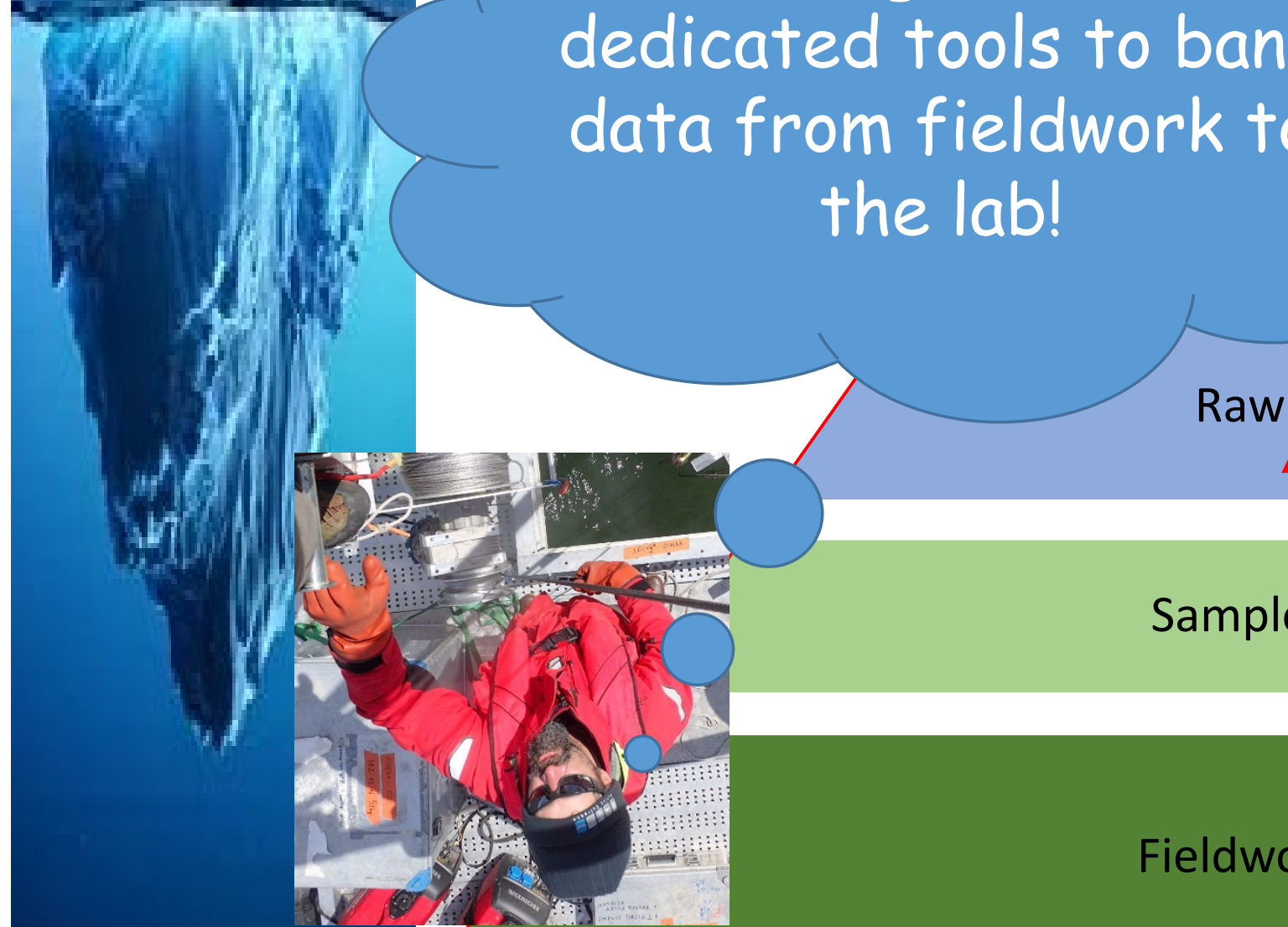

Although, they are the absolutely necessary foundations of the whole pyramid:

Samples and field data are often barely within the iceberg itself...

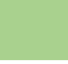


$\rightarrow$ Catching fieldwork data at the source: CoreBook Android App.

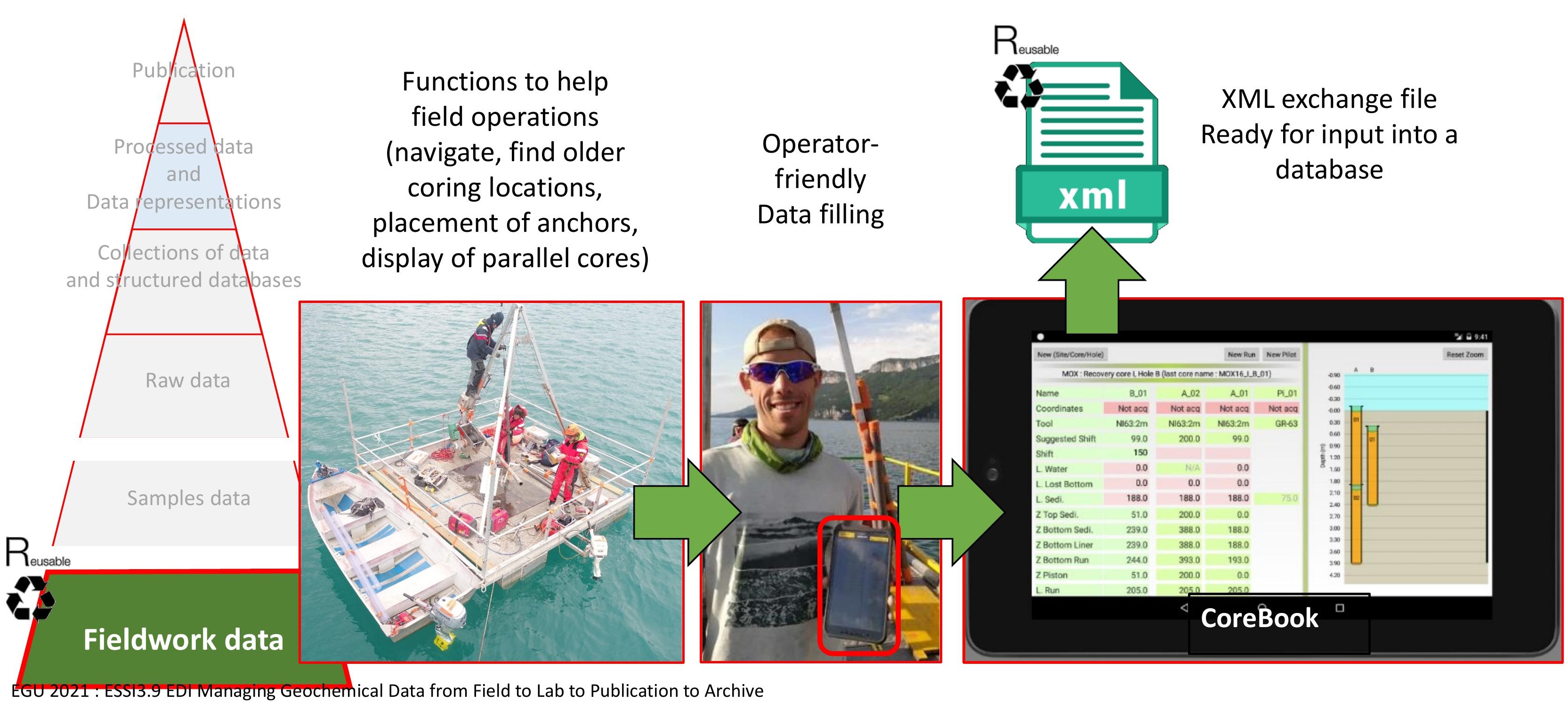


10 years of efforts in curating lake sediment cores and their associated results

$\rightarrow$ Banking and displaying fieldwork data: the National Cyber-core repository (Cyber-carothèque nationale)
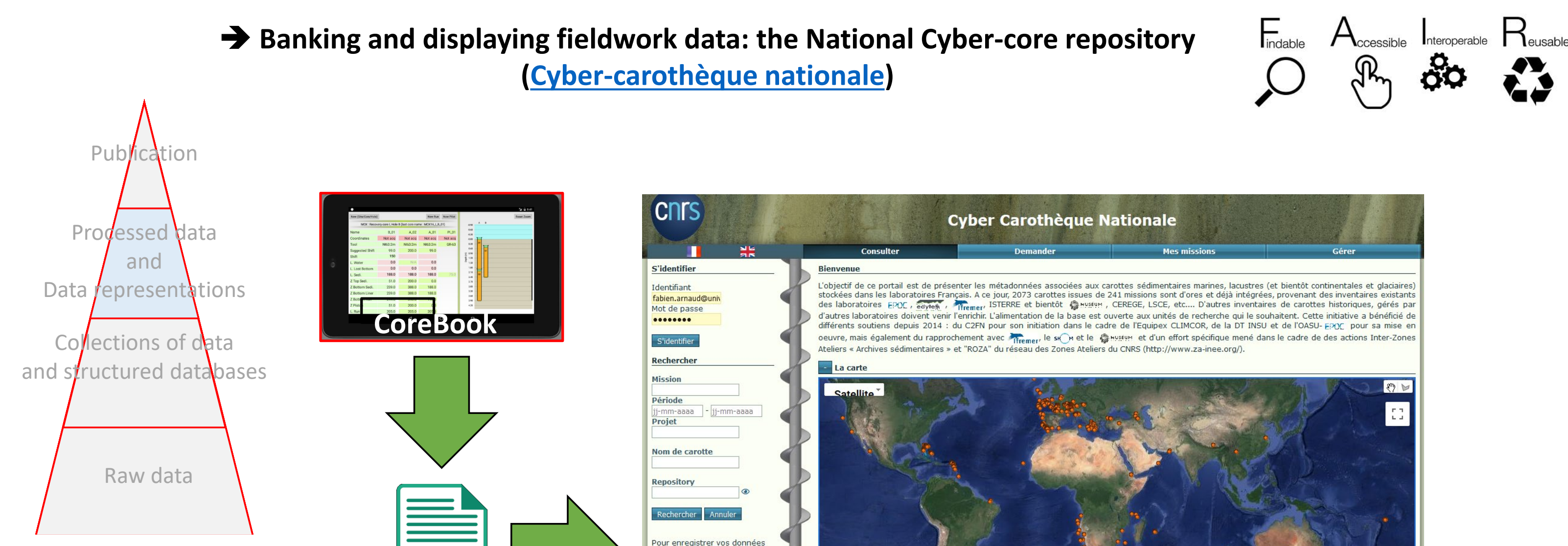

Samples data
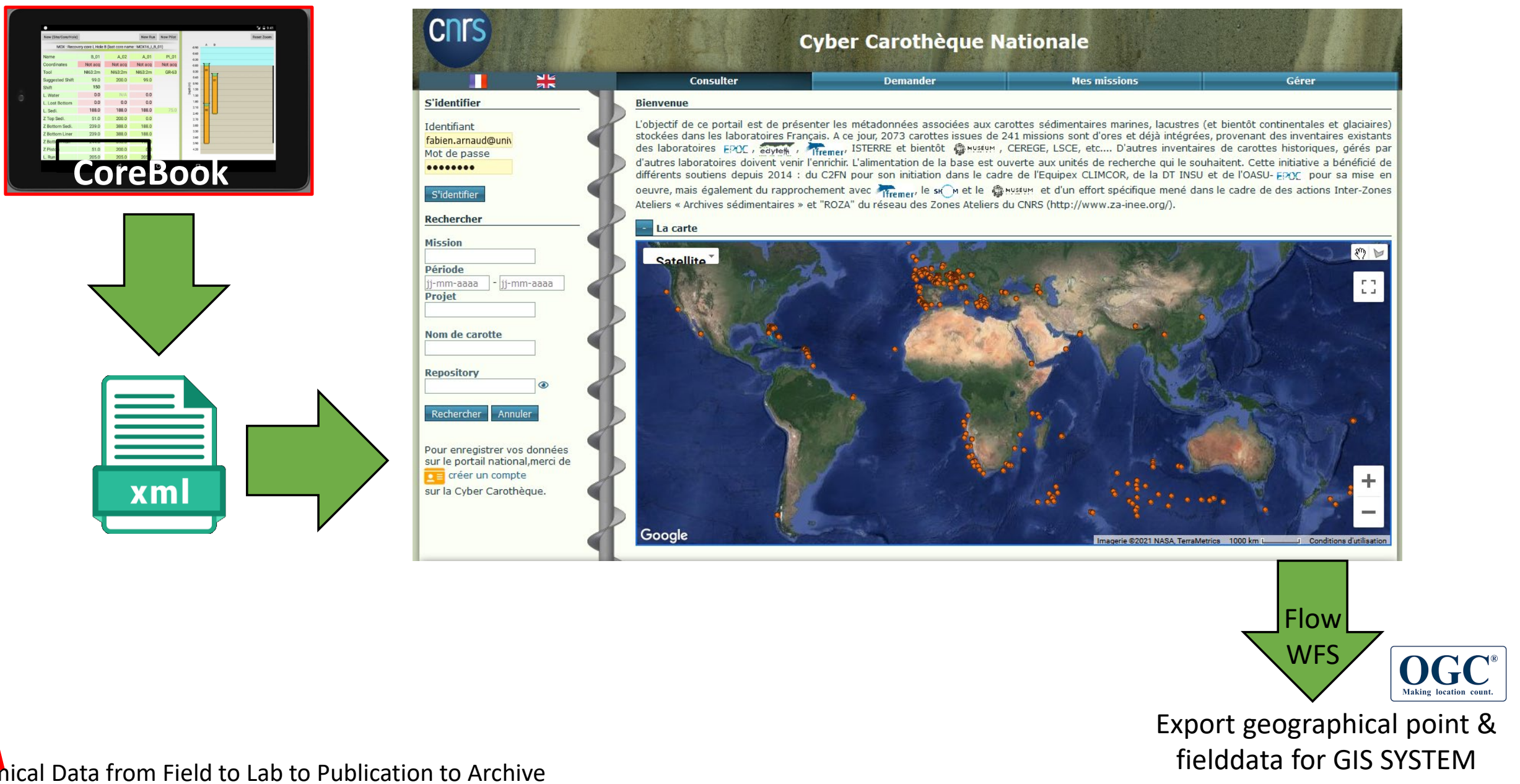

Fieldwork data

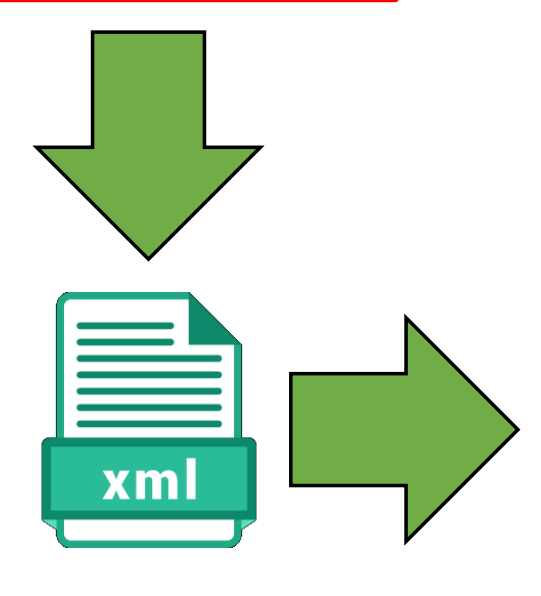


Banking and displaying fieldwork data: the National Cyber-core repository (Cyber-carothèque nationale)

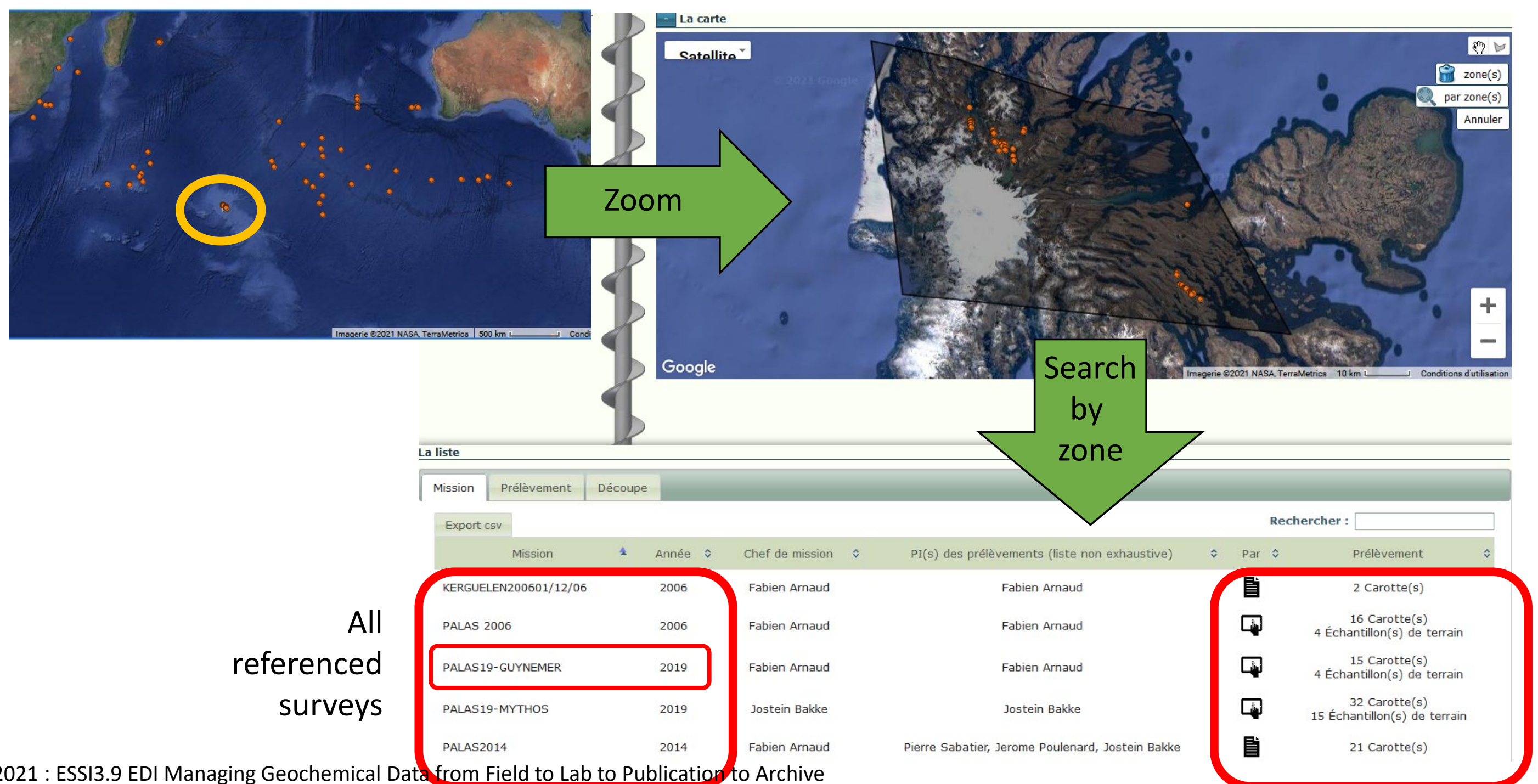

All referenced cores and samples 
Coring Technical Scheme for GUY19-1 on LAKE GUYNEMER 10 years of efforts in curating lake sediment cores and their associated results

$\rightarrow$ Banking and displaying fieldwork data: the National Cyber-core repository (Cyber-carothèque nationale)

\section{Mission information}

\section{Mission PALAS19-GUYNEMER}

Description

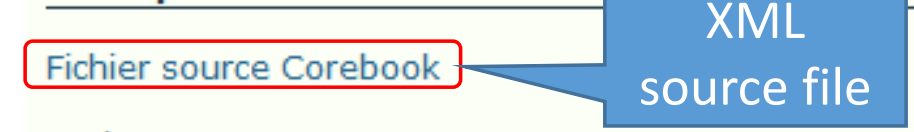

Code

Début de mission 27-11-2019 06:00

Fin de mission 27-11-2019 18:00

Description

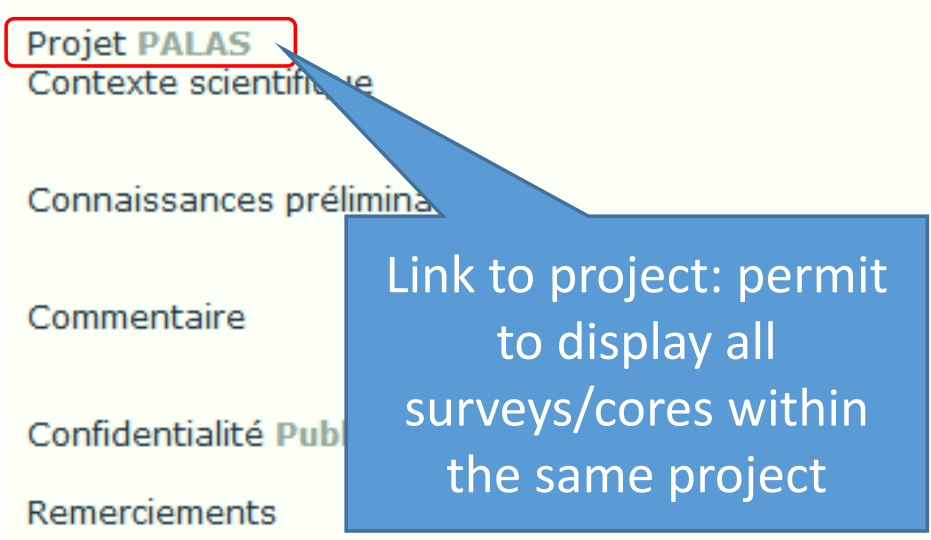

Remerciements

Automatic survey

report with DOI
Participants

Chef foreur Arnaud Fabien(iD)

Chef de mission Arnaud Fabien(iD)

PI(s) des prélèvements (liste non exhaustive) Arnaud Fabien (iD)

Financeur

Aucun(e)

Documents liés

GUY 19-I-Pil-05-20191223-141634.jpg GUY 19-I-Pil-05-20191223-141716.jpg GUY19-I-Pil-05-20191223-141736.jpg GUY19-I.20190619-195534.Coring.Schema.png GUY19-I-B-01-20191201-064036.mp4 EPGUY19-01-20191204-113555.jpg

EPGUY 19-01-20191204-113630.jpg

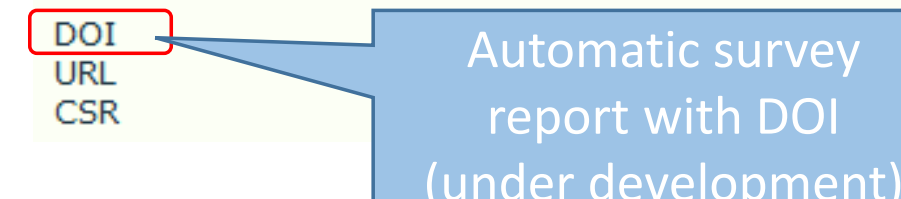

Any additionnal document (pictures, sounds, videos) taken with CoreBook App.

Acknowledgement of crew members with determined role and ORCID identification

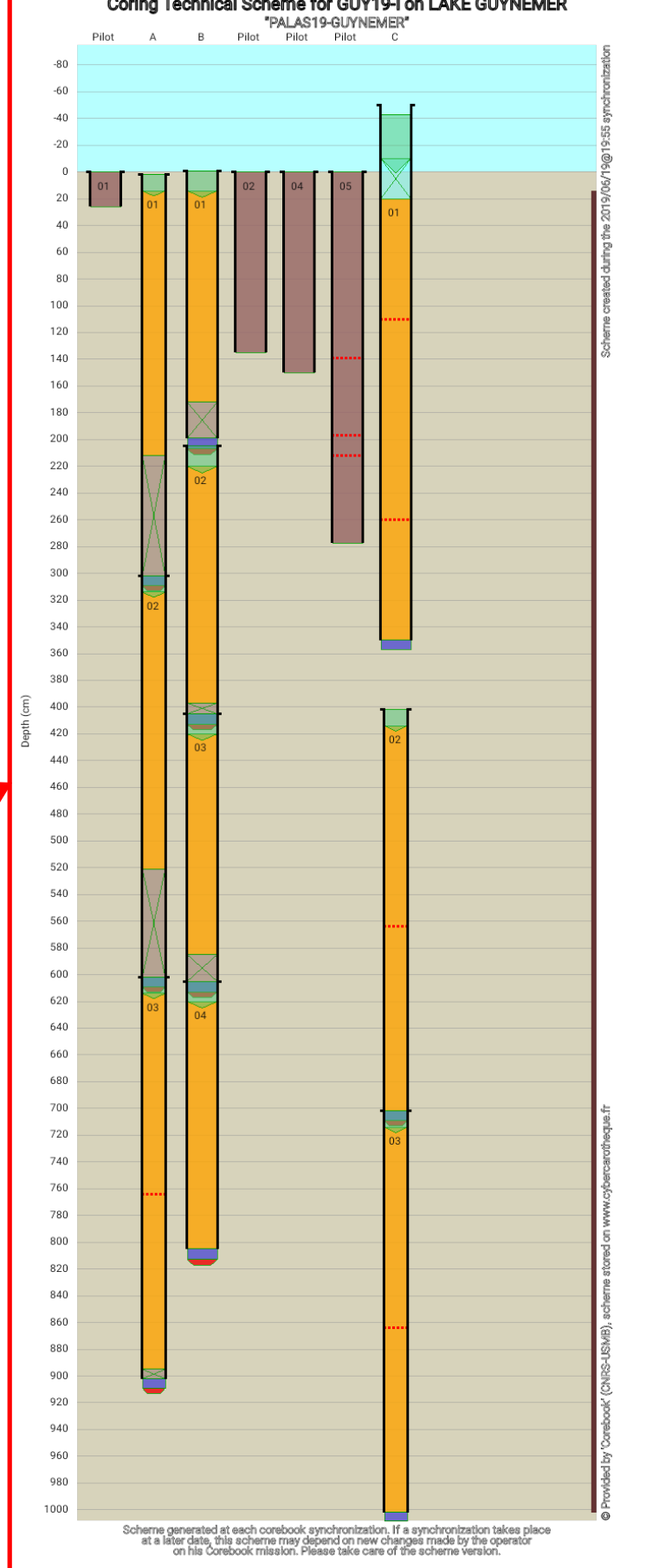

EGU 2021 : ESSI3.9 EDI Managing Geochemical Data from Field to Lab to Publication to Archive 


\section{$\rightarrow$ Banking and displaying fieldwork data: the National Cyber-core repository} (Cyber-carothèque nationale)

\section{Sample (core) information}

\begin{tabular}{l} 
Description \\
\hline No IGSN TOAE0000000078 \\
Site / Station GUY19-I \\
Nom GUY19-I-A-03 \\
Matériel Sediment \\
Type de prélèvement Carotte (recouvrement) \\
Environnement Étendue d'eau (douce) naturelle - Lac \\
Plateforme \\
Profondeur bathymétrique (m) 94 \\
Altitude (m) 131.0 \\
zone(s) French Southern and Antarctic Lands, France \\
Lieu LAKE GUYNEMER \\
Point GPS (WGS84, DD) -49.11344500 69.02049300 \\
Date 28-11-2019 16:01 \\
Nom du carottier U-NIEDERREITER 63-3m (EDY) \\
Nom de la configuration 2-NIED63-3m PO/TC (EDY) \\
Diamétre intérieur (mm) 63 \\
Longueur du prélèvement (m) 2.93 \\
Longueur matière récupérée (m) 2.81 \\
Époque géologique \\
PI Fabien Arnaud (iD \\
Sondeur/Foreur en chef \\
Commentaire
\end{tabular}

IGSN unique identifier

\section{Codified usual name :}

Site-Year-Station-Hole-Section

\section{Site-Year-Station-Hole-Section}
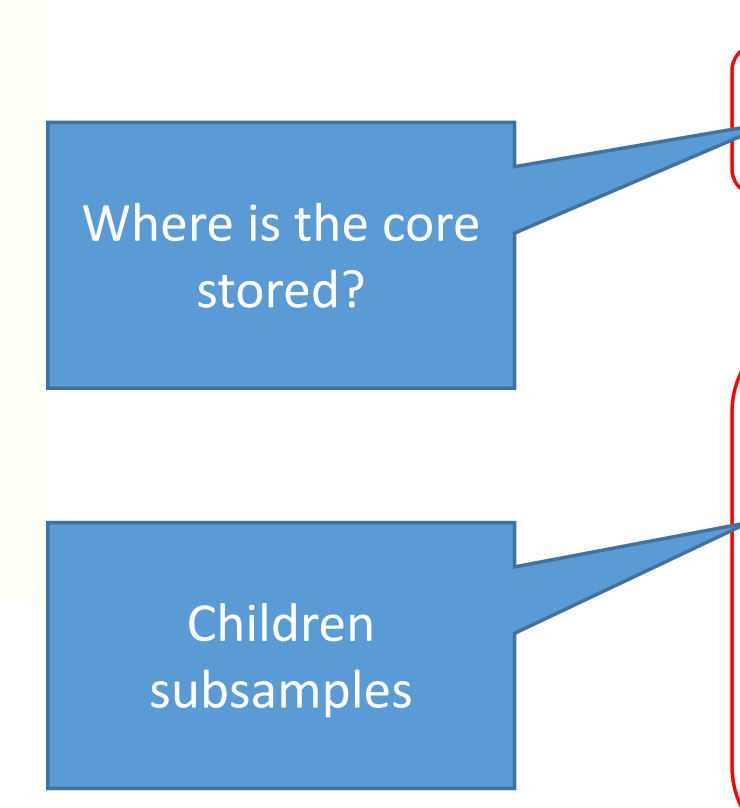

EGU 2021 : ESSI3.9 EDI Managing Geochemical Data from Field to Lab to Publication to Archive

Mission

Mission PALAS19-GUYNEMER

DOI / CSR

Début de mission 27-11-2019 06:00

Fin de mission 27-11-2019 18:00

Projet PALAS

Code projet (Reference)

Chef de mission Fabien Arnaud (iD

Sondeur/Foreur en chef Fabien Arnaud (iD)

Repository

Repository Environnements, DYnamiques et TErritoires de la Montagne (EDYTEM)

Documents liés

Aucun(e)

Sous-prélèvements associés

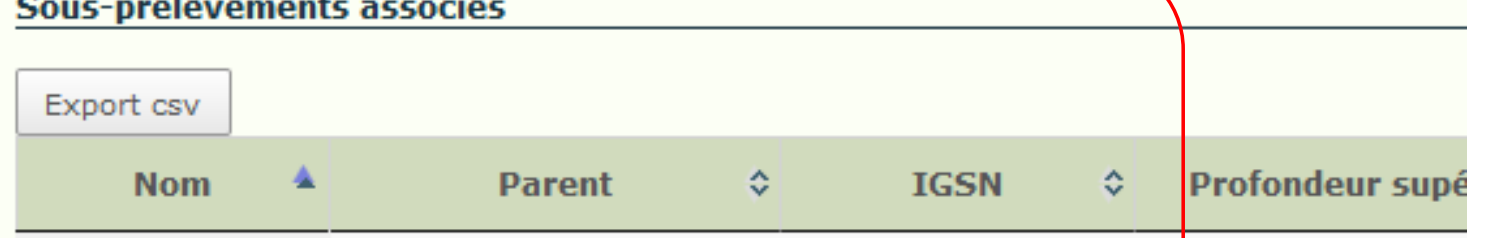

GUY19-I-A-03-A GUY19-I-A-03

Section Carotte (recouvrement)

TOAE0000000582

GUY19-I-A-03-B GUY19-I-A-03

Section Carotte (recouvrement)

TOAE0000000583 


\section{Banking and displaying fieldwork data: the National Cyber-core repository} (cyber-carothèque nationale)

\section{Coring tools information}

Configuration des outils

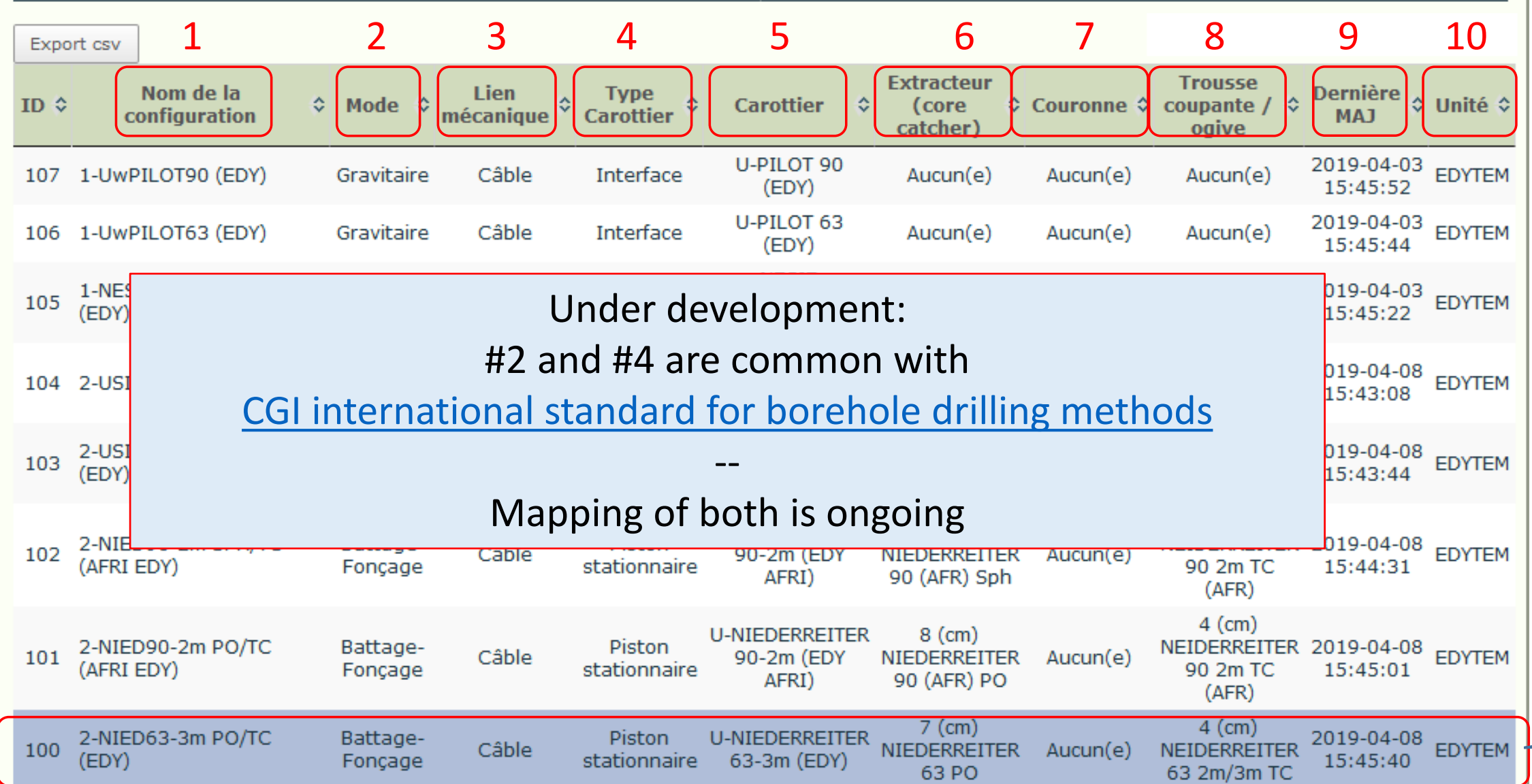
EGU 2021 : ESSI3.9 EDI Managing Geochemical Data from Field to Lab to Publication to Archive
Normalised description of any coring/drilling tool + its configuration

1- Name of the configuration 2- Mode (energy for penetration) 3- Link to the energy source 4- Type of corer

5- Usual name of the corer 6- Type of core catcher (if any) 7- Type coring bit (if any) 8- Type of cutting shoe (if any) 9- Latest update 10- Corer's owner 
The pyramid of data: case of field-based (geo)sciences

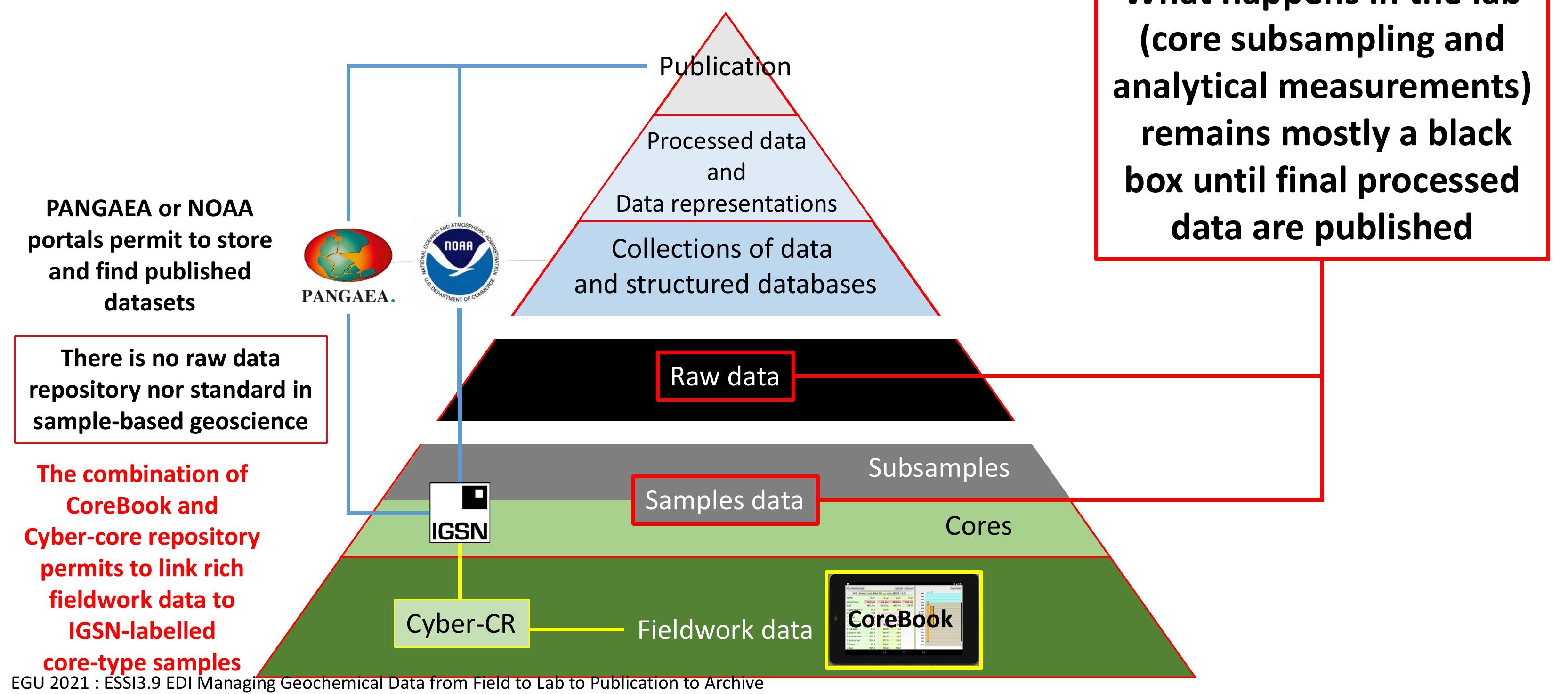

What happens in the lab (core subsampling and remains mostly a black remains mostly a black data are published 


\section{Remaining challenges are :}

The pyramid of data: case of field-based (geo)sciences

1) Curating core handling and subsampling data

2) Keeping track of previous operations (coring, subsampling, sample treatement) while analytical measurements are performed, together with analysis metadata

\section{Ongoing attempts}

1) Attempt to prolongate the cyber-core repository using Collec-Science software (not discussed here)

2) Prototype of an organised Paleodatabase for basic data: ROZA

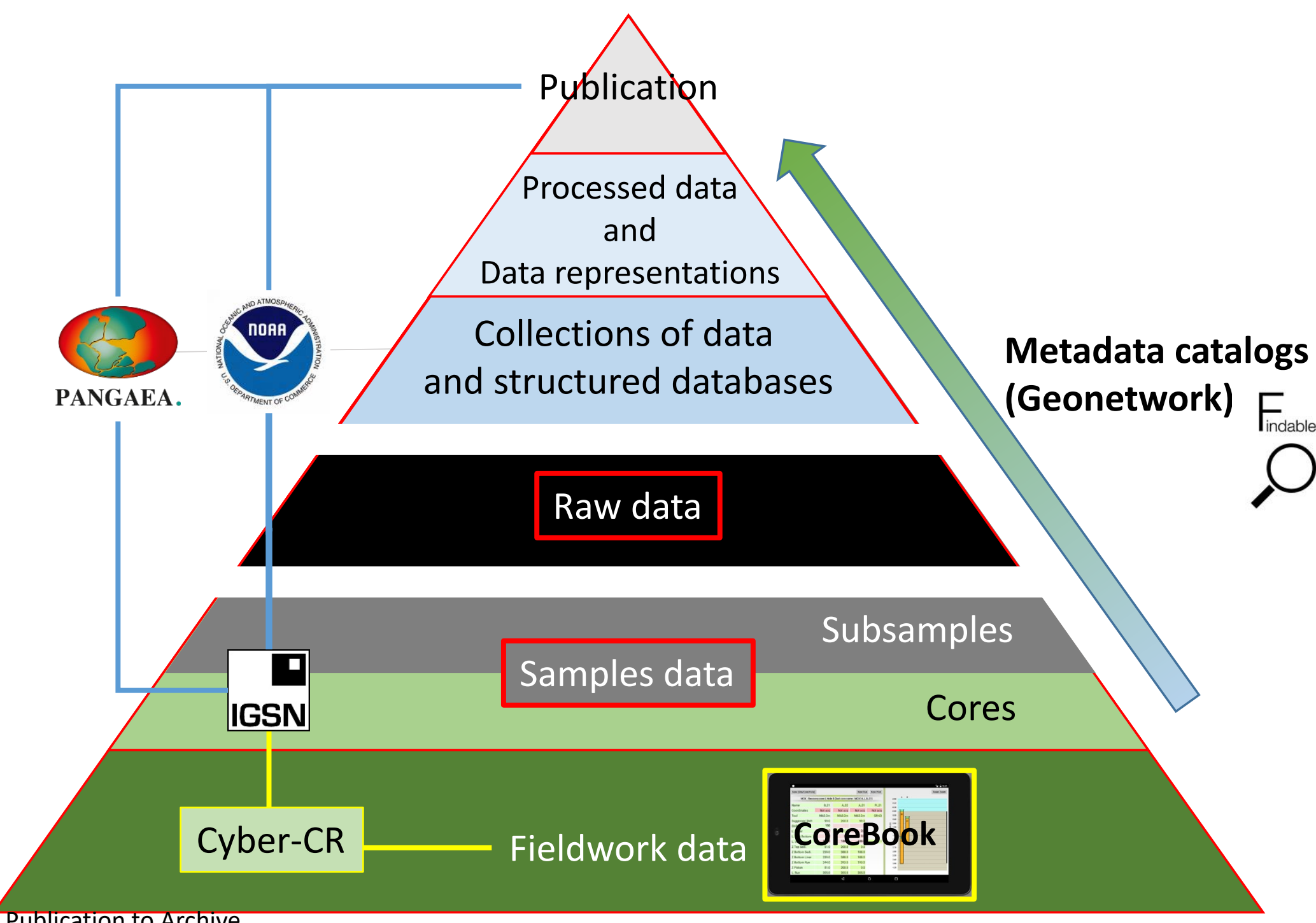


"French Zones Ateliers » are the French contribution to the international Long Term Environmental Research (eLTER) network

$$
R O Z A=\text { Retro-Observatory of Zones Ateliers portal }
$$

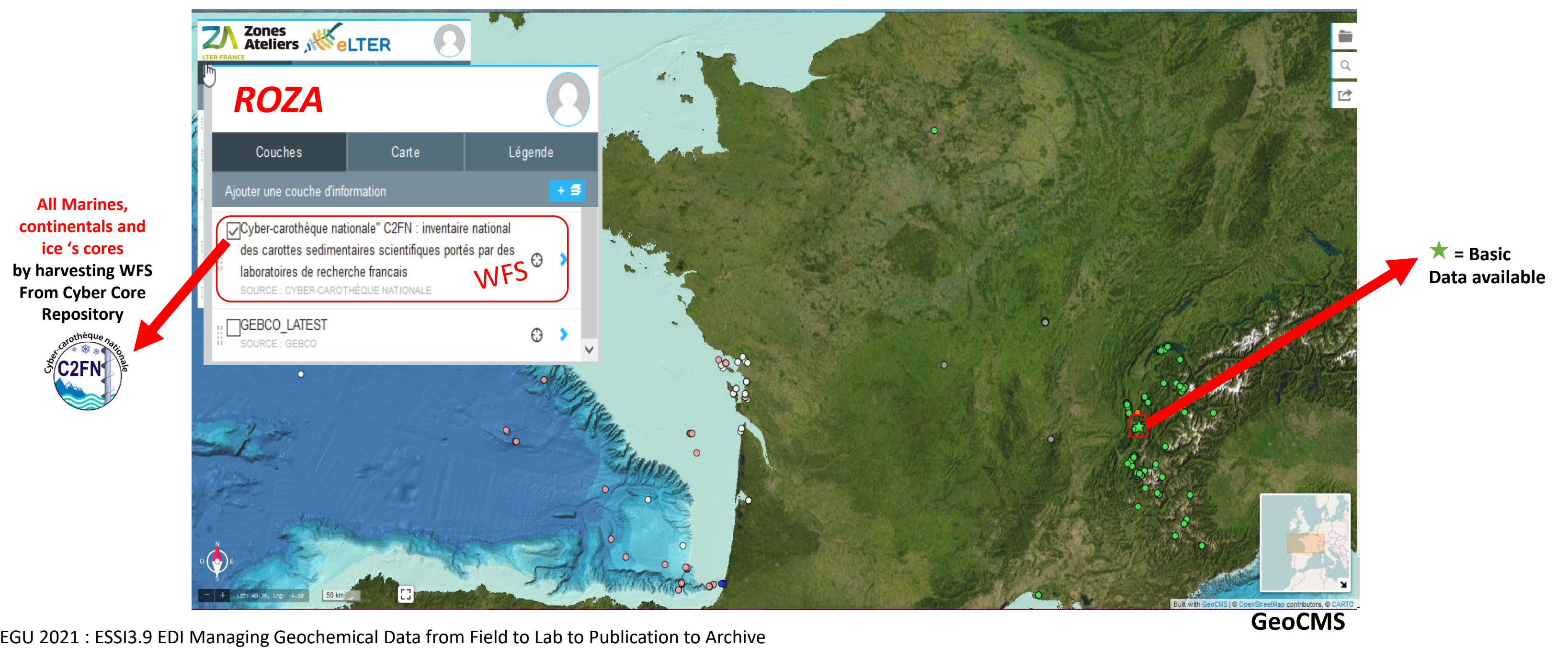




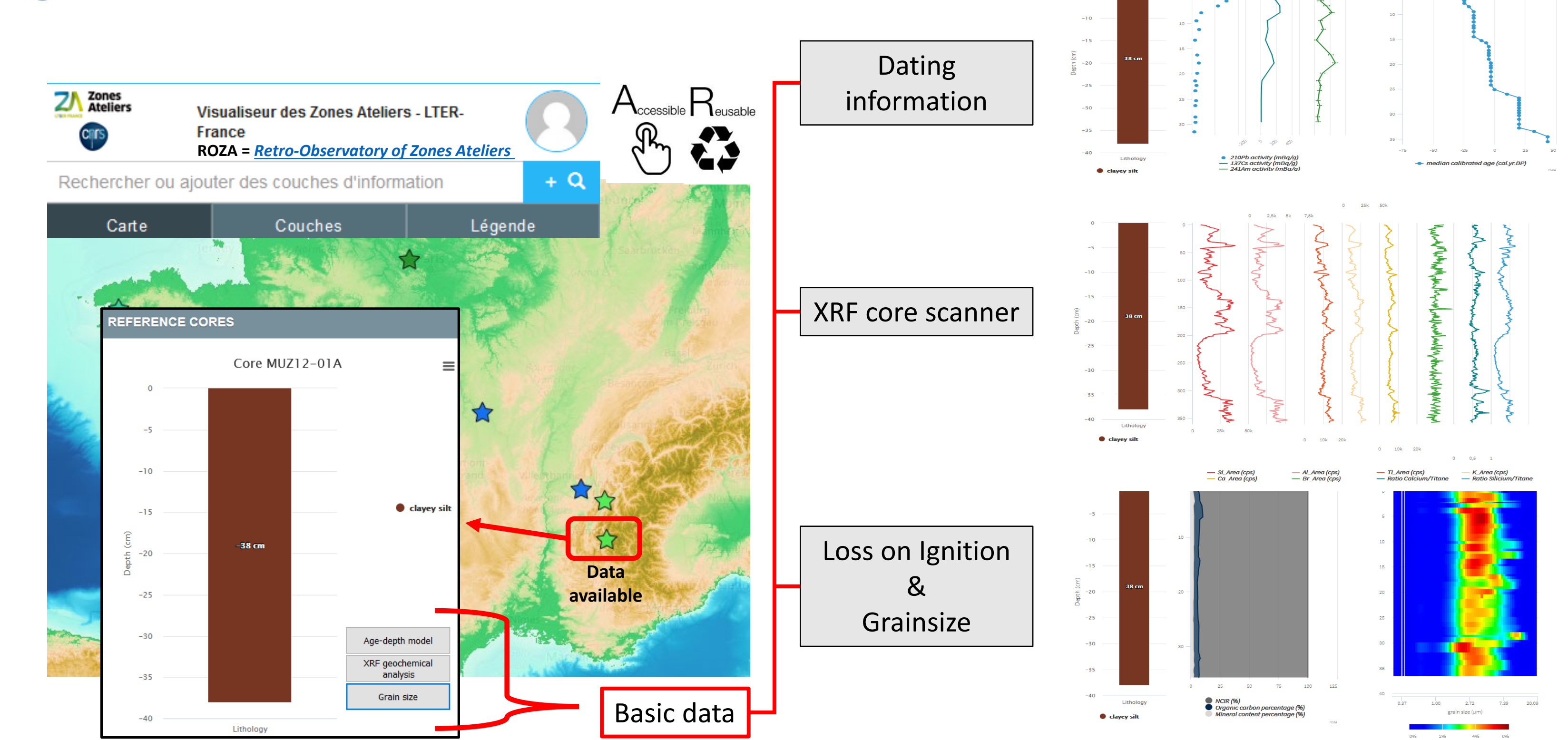
$\rightarrow$ ROZA aims at providing homogenised basic data to promote the re-use of sites, samples and data within the ZA network

EEGU Gaseral 2021 ESSI3.9 EDI Managing Geochemical Data from Field to Lab to Publication to Archive 
ROZA : standardised data \& metadata template

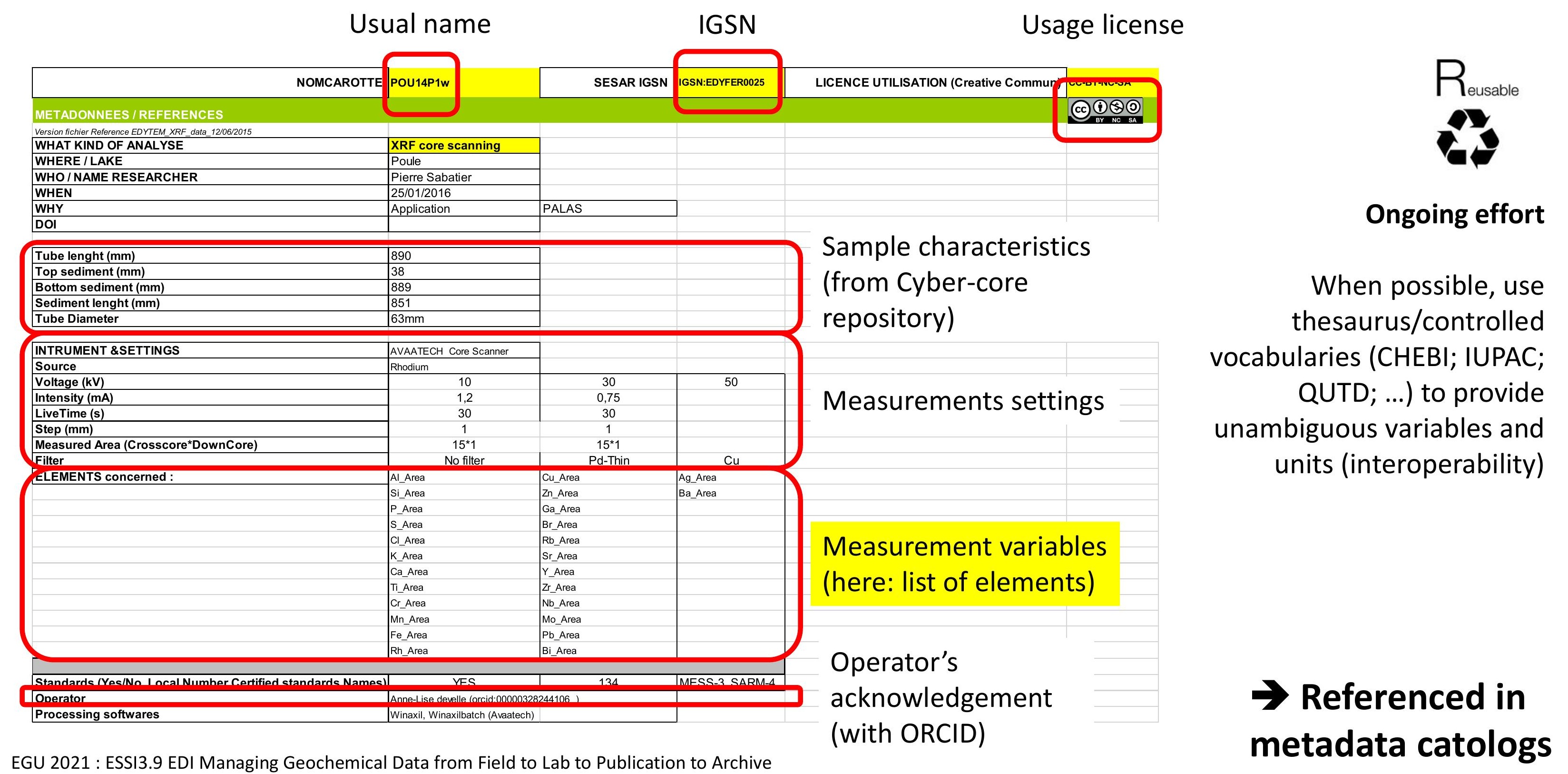

EGU 2021 : ESSI3.9 EDI Managing Geochemical Data from Field to Lab to Publication to Archive metadata catologs 


\section{Promote visibility \& interoperability} by metadata geocatalogue (ISO19.115)*

\section{Feature variables catalogue}

$H_{\text {eLTER }}$

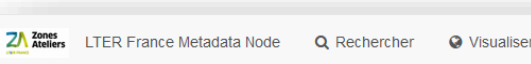

Accepter ou Quitter ce site

Q. Retour à la recherche

SLac de la Muzelle - Carottage Muz $12-1$ - Plant cover and erosion dynamics
impacts of pastoral activities and climatic changes over the last 1600 years impacts of pastoral activities
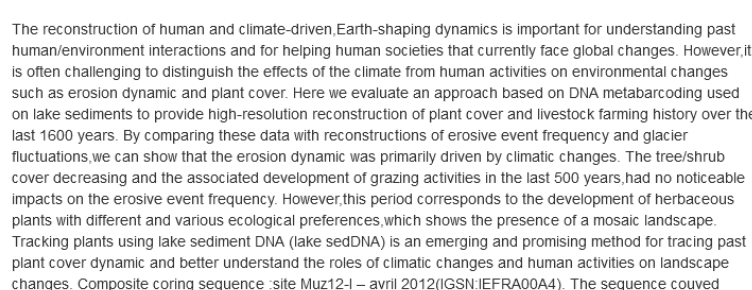

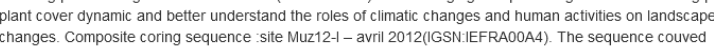
périod from 303 to 2012 -year).LT

Bo zone Atelier Apes

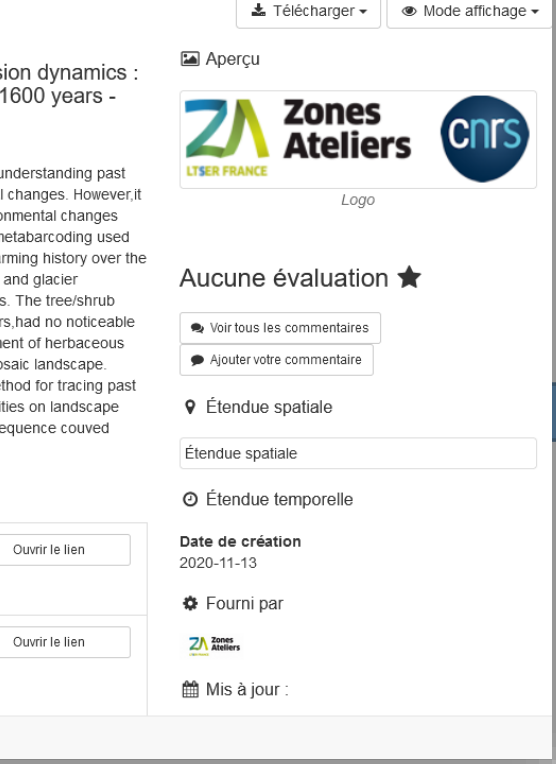

LTSER Zone Adele- Apes - Mastersite Lautaret-

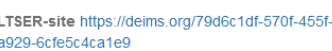

* Create by R workflow "Geoflow "
Link with vocabulary

EGU 2021 : ESSI3.9 EDI Managing Geochemical Data from Field to Lab to Publication to Archive

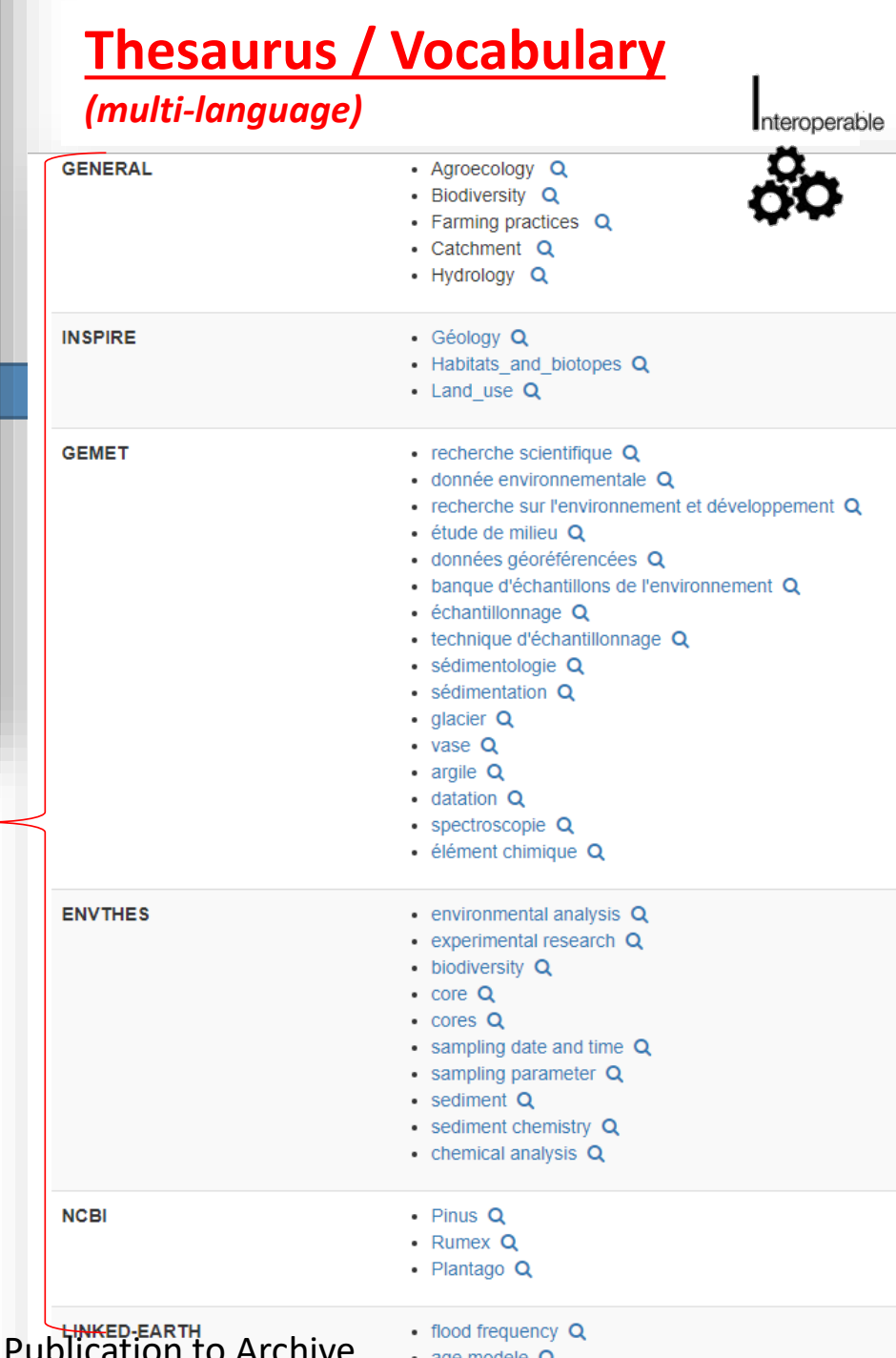

团 Dictionnaire de données (Inter-ZA ROZA) : SHORT LIVE INUCLIDES Technical information

Name

210 Pb Energy (keV) (FLOAT)

210Pb_ACTIVTYY (MBq/g) (FLOAT)

210Pb_ACTVITY_uncert (mBq/g)

226Ra_ACTIVITY (mBq/g) (FLOAT)

226 RaEnergy (keV) (FLOAT)

226Ra_AC TIVITY_uncert (mBq/g)

137 CsEnergy (keV) (FLOAT)

137CS_ACTIVITY (mBq/g) (FLOAT)

137Cs_ACTIVITY_uncert (mBQ/g)

(F.

241 Am Energy (keV) (FLOAT)

241Am_ACTIVITY (mBa/g) (FLOAT)

团 Uictionnaire de donnees

Technical information

Name

Grain moyen (REAL)

Classement (FLOAT)

Q90 (REAL)

Q99 (REAL)

Feature catalog

曲

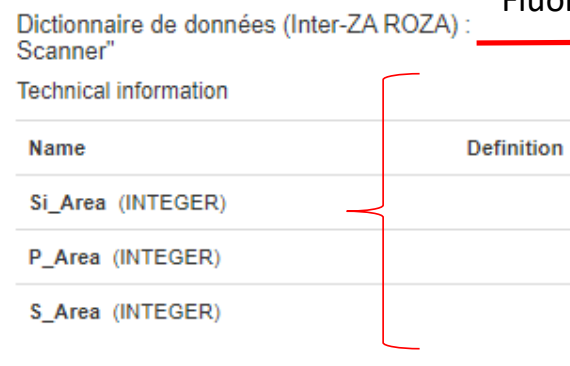

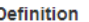

A) Grainsize Measurement variables

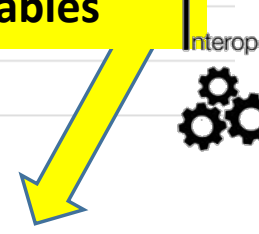

uoresence $X$

List of values 


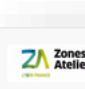

\section{Interoperability by Geocatalogue métadonnées (ISO19115)}

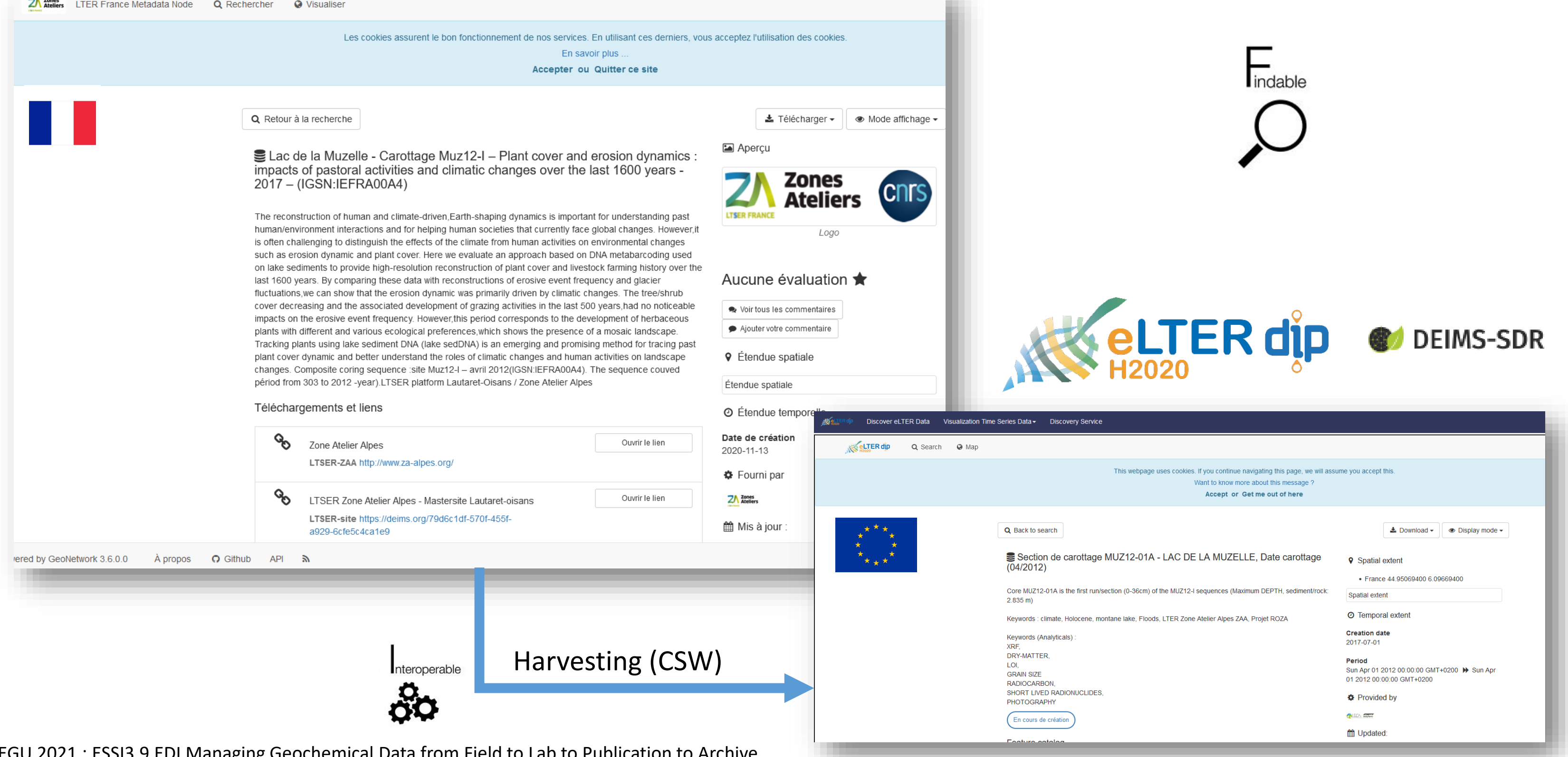




\section{Achievements}

With ROZA, it is possible to get a dataset that is linked to its:

- measurement metadata (LTER catalogue)

- sample data (IGSN)

- Fieldwork data (Cyber-Core repository)

Remaining challenges are :

- ROZA is just a prototype (with lot of flaws!)

- Propose an user-friendly workflow to inject data

- Deal with sub-samples (currently, only the core level is treated)

- Extend the database (only 4 cores...)

- Include treated data: age-models instead of dating data $\rightarrow$ SERAC
The pyramid of data: case of field-based (geo)sciences

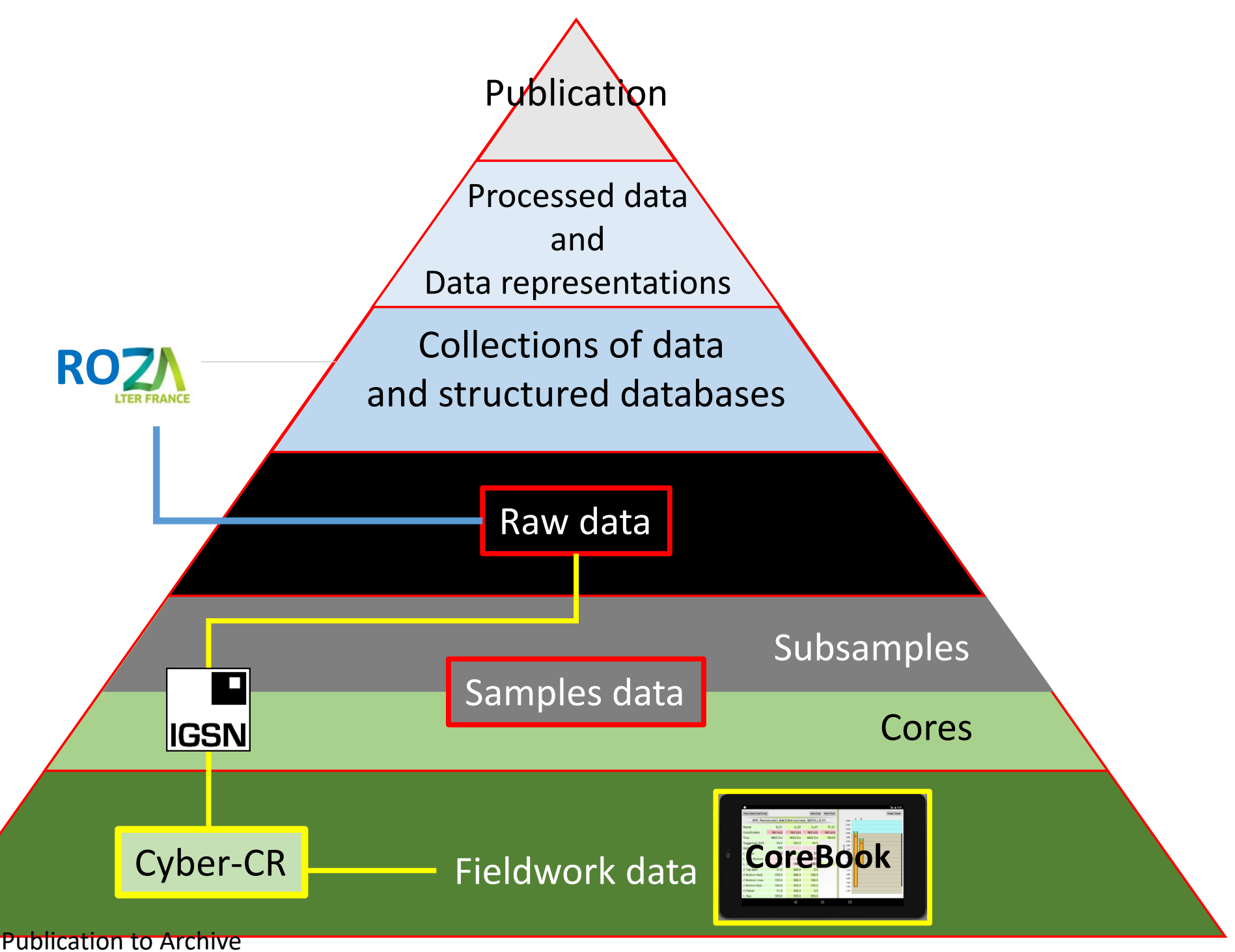


Metadata fields including IGSN and cyber-core repository references

ROZA-like standardised data template
Standardised data representation
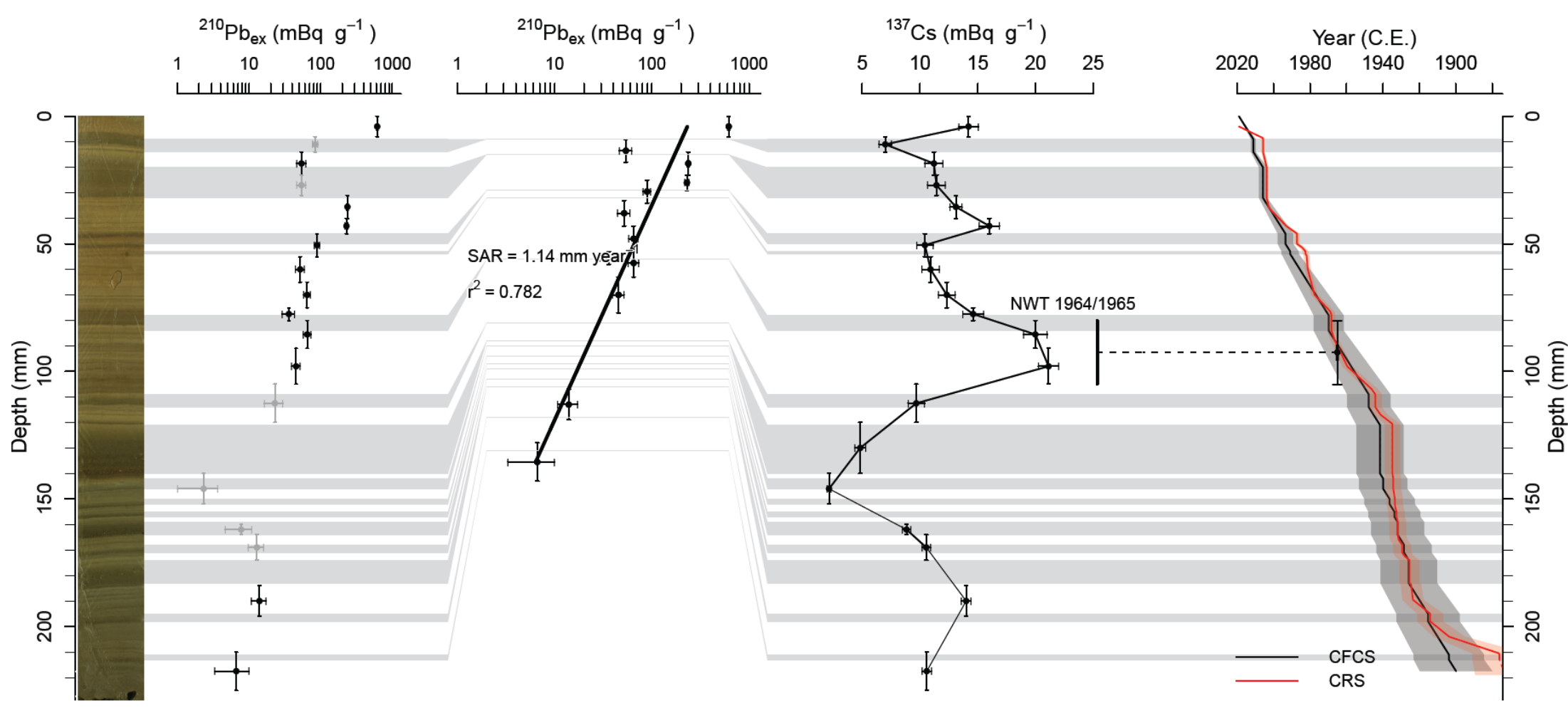

Standardised treated data with reproducible protocol 


\section{Corebook}

- Gathers standardised fieldwork data

\section{Cyber-core repository}

- Banks fieldwork data

- Links rich fieldwork data with IGSN

IGSN

- Provides unique identifier for upper levels

\section{ROZA}

- Standardised dataset linked with:

- measurement metadata (LTER catalogue)

- sample data (IGSN)

- Fieldwork data (Cyber-Core repository)

\section{SERAC provides:}

- A publishable standardised representation of radionuclide data

- A standardised age model file with a reproducible protocol

- Links to underlying levels of the pyramid

In the case of radionuclide dating, it is possible to link all levels of the pyramid
Limits

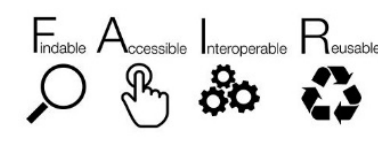

EGGU Ganereal 2021 ESSI3.9 EDI Managing Geochemical Data from Field to Lab to Publication to Archive

- ROZA is just a protoype, not used in routine

- $\quad$ Not yet satisfying management of subsamples

- No generalised use of Lab. Information systems

- No ongoing projects to standardize other types treated of paleo-data

\section{and structured databases \\ Collections of data} - Needs more integration within international projects

\section{Cyber-CR}

Cores

CoreBook 